\section{Vorsicht vor flüchtigen Sexualkontakten in tropischen Ländern}

\section{Bei Urlaubsreisen in tropische Länder besteht bei flüchtigen Sexual- kontakten Gefahr durch venerische Infektionen. Bei der reisemedizinischen Beratung sollte daher unbedingt auf die entsprechenden Risiken und auch die Verwendung von Kondomen hingewiesen werden.}

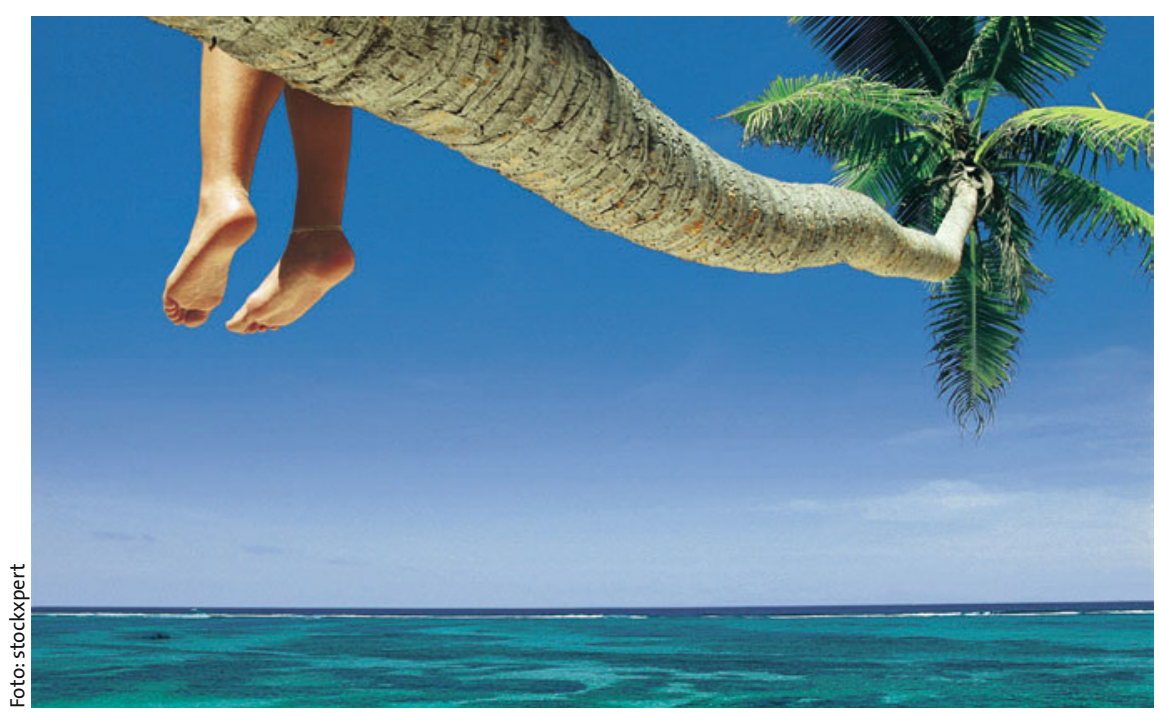

Der ideale Ort für einen Urlaubsflirt

eisen gilt als ein wesentlicher Faktor bei der Verbreitung von sexuell übertragbaren Infektionen (STD), da oftmals zu Hause geltende gesellschaftliche Tabus überschritten werden. Manche Reisende beiderlei Geschlechts planen sexuelle Abenteuer während des Urlaubs auch bewusst ein. Studien aus mehreren europäischen Ländern zeigten, dass es bei 5 bis $51 \%$ der Kurzzeitreisenden zu flüchtigen Sexualkontakten im Reiseland kommt. Bei Langzeitreisenden ist die Rate sogar noch höher. Nach
Schätzungen verwenden dabei nur 2475\% Kondome.

In der vorliegenden Studie aus Frankreich wurden Tropenreisende hinsichtlich ihres Sexualverhaltens im Reiseland befragt. Alle hatten sich während eines Zeitraum von zwölf Monaten in einer Tropenambulanz wegen mukokutaner Beschwerden vorgestellt, die auf eine STD hinwiesen. In der Studie konnten die Daten von 49 Patienten (zwölf Frauen und 37 Männer, Durchschnittsalter 36,4 Jahre, 35 heterosexuell) ausgewertet werden. Vier Personen waren mit ihrem Lebenspartner gereist. 45 Personen hatten flüchtige sexuelle Kontakte im Reiseland, davon 31 mit Einheimischen und 14 mit anderen Touristen.

Am häufigsten fand sich als Diagnose eine Gonokokken-Urethritis $(\mathrm{n}=18)$, gefolgt von einer Infektion mit Herpessimplex-Virus Typ $2(\mathrm{HSV}-2 ; \mathrm{n}=12)$, weiter nicht näher diagnostizierbare Urethritiden ( $n=9$ ), eine Chlamydia-trachomatis-Infektion $(n=4)$, Syphilis Stadium I $(n=4)$ sowie HIV-Infektionen $(n=2)$. Bei der Gonokokken-Urethritis, die in Asien und Afrika akquiriert wurde, fiel bei 25\% eine verminderte Empfindlichkeit gegen Fluorchinolone auf. Auffällig war, dass es neben den genitalen Affektionen bei HSV-2 und Syphilis zudem zu oralen Läsionen gekommen war.

Kommentar: Die Studie zeigt das Spektrum von Geschlechtskrankheiten, wie sie bei Reisen in tropische Länder als Folge flüchtiger Sexualkontakte möglich sind. Zwar handelt es sich hier nicht um eine systematische Untersuchung, jedoch geben die Daten einen guten Eindruck über dieses gesundheitliche Problem. Bei der reisemedizinischen Beratung wird oftmals nicht auf die besonderen Gefahren durch Geschlechtserkrankungen hingewiesen. Auch zeigen diese Ergebnisse, dass der Gebrauch von Kondomen bei flüchtigen Sexualkontakten nicht immer konsequent beachtet wird.

\section{T. F. Schwarz}

Ansart $S$ et al. Sexually transmitted diseases diagnosed among travelers returning from the tropics. J Travel Med 2009; 16: 79-83 